\title{
PERENCANAAN IPAL BIOFILTER ANAEROB-AEROB DI PUSKESMAS WAY HALIM KOTA BANDAR LAMPUNG
}

\author{
Rahmat Fauzi Rama Dani ${ }^{1 *}$ \\ ${ }^{1}$ Politeknik Kesehatan Kemenkes Tanjungkarang
}

\section{Artikel Info :}

Received 13 Februari 2022 Accepted 24 Februari 2022 Available online 28 Februari 2022

Editor: Amrul Hasan

Keyword :

Wastewater, biofilter, aerobic, anaerobic, WWTP

Kata kunci :

Air limbah, biofilter, aerob, anaerob, IPAL

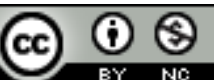

Ruwa Jurai: Jurnal

Kesehatan Lingkungan is licensed under a Creative Commons

Attribution-NonCommercial 4.0

International License.

\begin{abstract}
Puskesmas Way Halim produces wastewater around $25.7 \mathrm{m3} /$ day. Based on the regulations, processing should be carried out before being discharged into the environment. The research aims to design a Wastewater Treatment Plant (WWTP) with aerobic and anaerobic biofilter systems following applicable requirements. The research is descriptive, beginning with data collection through observation and interviews. Furthermore, measurements and calculations are used to make the WWTP design. The results of the study determined that the volume of the fat trap tank $=2.1 \mathrm{m3}$, an equalization tank $=6.4 \mathrm{m3}$, an initial settling tank $=4.3 \mathrm{m3}$, an anaerobic tank $=4.8 \mathrm{m3}$, anaerobic tank $=2.9 \mathrm{m3}$, final settling basin $=4.3 \mathrm{m3}$, biocontrol tank $=4.3 \mathrm{m3}$ and chlorination tank $=1 \mathrm{~m} 3$. The estimated cost required for the construction of the installation is Rp. 156,000,000. This design is believed to reduce BOD up to $94 \%$ (from 124.9 $\mathrm{mg} / \mathrm{l}$ to $10.8 \mathrm{mg} / \mathrm{l}$ ), thus meeting the applicable regulations.

Puskesmas Rawat Inap Way Halim menghasilkan air limbah sebanyak 25,7 $\mathrm{m}^{3} /$ hari. Berdasarkan peraturan yang berlaku, sudah seharusnya dilakukan pengolahan sebelum dibuang ke lingkungan. Penelitian bertujuan merancang Instalasi Pengolahan Air Limbah (IPAL) dengan sistem Biofilter anaerob-aerob, sesuai dengan persyaratan yang berlaku. Penelitian bersifat deskriptif, diawali dengan pengumpulan data melalui pengamatan dan wawancara. Selanjutnya dilakukan pengukuran dan perhitungan sebagai bahan pembuatan rancangan IPAL. Hasil penelitian diketahui bahwa volume bak penangkap $=2,1 \mathrm{~m}^{3}$, bak ekualisasi $=6,4 \mathrm{~m}^{3}$, bak pengendap awal $=4,3 \mathrm{~m}^{3}$, bak anaerob $=4,8 \mathrm{~m}^{3}$, bak aerob $=2,9 \mathrm{~m}^{3}$, bak pengendap akhir = $4,3 \mathrm{~m}^{3}$, bak biokontrol $=4,3 \mathrm{~m}^{3}$ dan bak klorinasi $=1 \mathrm{~m}^{3}$. Perkiraan biaya yang dibutuhkan untuk pembangunan instalasi sebesar $R p$ 156.000.000. Rancangan ini diyakini mampu menurunkan BOD hingga 94\%, (dari 124,9 mg/l menjadi 10,8 mg/l), sehingga memenuhi peraturan yang berlaku.
\end{abstract}

Corresponding author: : Rahmat Fauzi Rama Dani

Jl. Soekarno-Hatta No 6, Bandar lampung, Lampung. Indonesia Email: rahmatfauziramadani@gmail.com

\section{PENDAHULUAN}

Pusat kesehatan masyarakat (puskesmas) adalah fasilitas pelayanan kesehatan yang menyelenggarakan upaya kesehatan masyarakat dan perseorangan tingkat pertama, dengan lebih mengutamakan upaya promotif dan preventif di wilayah kerjanya. Berdasarkan bentuk pelayanannya, dibedakan menjadi puskesmas non rawat inap dan puskesmas rawat inap. Puskesmas rawat inap merupakan diberi tambahan sumber daya untuk menyelenggarakan rawat inap pada pelayanan persalinan normal dan pelayanan rawat inap pelayanan kesehatan lainnya (Kementerian Kesehatan RI, 2019b).

Berdasarkan data Kemenkes 2018, jumlah puskesmas keseluruhan di Indonesia sebanyak 9.993 unit, terdiri dari puskesmas rawat inap (3.623) dan non rawat inap (6.370). Provinsi Lampung saat ini telah memiliki 302 unit, terdiri dari puskesmas rawat inap (119) dan non rawat inap (183). Sedangkan di Bandar Lampung 
terdapat 13 unit puskesmas rawat inap, dan 17 unit non rawat inap (Kementerian Kesehatan RI, 2019a). Namun, hingga saat ini hanya terdapat $31 \%$ puskesmas yang belum memiliki instalasi pengolahan air limbah (IPAL), salah satunya adalah Puskesmas Rawat Inap Way Halim. Menurut Kementerian Kesehatan RI, (2019c), setiap pelayanan kesehatan diwajibkan memiliki IPAL. Demikian pula menurut Peraturan Menteri Kesehatan Nomor 43 Tahun 2019, juga menyebutkan bahwa puskesmas harus memiliki sistem pengolahan air limbah medis dan nonmedis yang memenuhi persyaratan kesehatan, sehingga aman di buang ke badan air atau resapan tanah (Kementerian Kesehatan $\mathrm{Rl}$, 2019b).

Puskesmas Rawat Inap Way Halim berlokasi di Kecamatan Kedaton, Kota Bandar Lampung. Dalam pelaksanaan kegiatannya, air limbah yang dihasilkan sebanyak $25,7 \mathrm{~m}^{3} /$ hari. Sumber air limbah terutama berasal dari ruang perawatan (ruang rawat inap), buangan kamar mandi, dapur, air limbah laboratorium, ruang tindakan, dan dapur. Menurut (Said, 2018), air limbah puskesmas termasuk kategori limbah domestik, dengan karakteristik fisik $(\mathrm{pH}$, suhu, warna dan lain-lain), kimia (BOD, COD, DO), dan biologis (E-Coli dan Coliform), sehingga harus diolah sebelum dibuang ke badan air. Air limbah yang dibuang ke badan air tanpa pengolahan dapat menyebabkan gangguan ekologi dan berisiko terhadap kesehatan manusi (Asmadi dan Suharno, 2012; Hariyani \& Sarto, 2018; Timpua \& Pianaung, 2019; Widayat \& Said, 2017)

Salah satu teknologi pengolahan air limbah yang dapat diaplikasikan untuk pengolahan limbah cair puskesmas adalah Biofilter anaerobaerob (Hariyani \& Sarto, 2018; Timpua \& Pianaung, 2019; Widayat \& Said, 2017). Teknologi ini banyak dikembangkan karena memiliki beberapa keunggulan dibanding metode lainnya, yaitu 1) pengolahannya sangat mudah dan biaya operasionalnya murah, 2) tidak perlu lahan yang luas, 3) tertutup dan bebas bau, 4) dapat digunakan untuk air limbah dengan beban BOD yang cukup besar, 5) dapat menghilangkan padatan tersuspensi dengan baik dan lumpur yang dihasilkan relatif sedikit.
Penelitian bertujuan untuk membuat perencanaan IPAL dengan sistem Biofilter anaerob-aerob, serta memperkirakan kebutuhan biaya pembangunannya. Diharapkan hasil penelitian ini memberikan sumbangan informasi/masukan bagi Puskesmas Rawat Inap Way Halim Kota Bandar Lampung dan Dinas Kesehatan Kota Bandar Lampung dalam pengolahan air limbah khususnyapuskesmas.

\section{METODE}

Metode penelitian bersifat deskriptif untuk menghasilkan perencanaan IPAL di Puskesmas Rawat Inap Way Halim Kota Bandar Lampung. Pengumpulan data dengan wawancara dan observasi. Pengukuran dilakukan untuk mendapatkan data volume air limbah yang dihasilkan, serta luas lahan yang tersedia. Luas lahan berkaitan dengan ukuran IPAL yang direncanakan.

Perencanaan desain IPAL menggunakan tujuh tahap pengolahan mengikuti Kementerian Kesehatan RI (2011), yaitu bak pemisah lemak, bak pengumpul, bak pengendap awal, bak anaerob, bak aerob, bak pengendap akhir, dan biokontrol. Perhitungan untuk mendapatkan ukuran (volume) pada setiap tahap pengolahan menggunakan formula pada Tabel 3.

Beberapa asumsi dan ketetapan yang digunakan adalah (Kementerian Kesehatan RI, 2011): HRT bak pemisah lemak = 1jam; HRT bak pengumpul $=6$ jam; Efisiensi Pengolahan BOD = 25\%; HRT bak pengendap awal $=4$ jam; Efisiensi pengolahan BOD bak anaerob $=66,7 \%$; HRT bak anaerob $=6$ jam; Standar Beban BOD/Volume Media $=0,4-4,7 \mathrm{~kg} \mathrm{BOD} / \mathrm{m}^{3} ;$ Volume media bak anaerob $=50 \%$ dari total volume reaktor; Efisiensi Pengolahan BOD bak aerob $=53,3 \%$; HRT bak aerob $=6$ jam; Standar Beban $\mathrm{BOD} /$ Volume Media $=0,4-4,7 \mathrm{~kg} \mathrm{BOD} / \mathrm{m}^{3}$.

\section{HASIL dan PEMBAHASAN}

Sumber limbah pada Puskesmas Rawat Inap Way Halim berasal dari ruang rawat inap, mushola, laboratorium, ruang tindakan, toilet dan dapur. Debit limbah dihitung berdasarkan kebutuhan air bersih pelayanan kesehatan, yaitu 200 liter/TT/hari. Saat ini, puskesmas memiliki 11 tempat tidur (TT), dan direncanakan 5 TT tambahan pada 10 tahun ke depan. Kebutuhan 
air untuk karyawan sebanyak 40 liter/orang dan kebutuhan air pengunjung 8 liter/orang. Dari perawatan $\left(3 \mathrm{~m}^{3}\right)$, jumlah karyawan $\left(1,7 \mathrm{~m}^{3}\right)$, dan data tersebut, maka total debit air limbah jumlah rata-rata kunjungan rawat jalan $\left(21 \mathrm{~m}^{3}\right)$. sebanyak 25,7 m3, berdasarkan jumlah TT ruang

Tabel 3. Formula yang digunakan dalam perhitungan

\begin{tabular}{|c|c|c|}
\hline Bak pemisah lemak: & $=\frac{\mathrm{HRT}}{24 \text { jam } / \text { hari }} \times \mathrm{Q}$ (debit) & 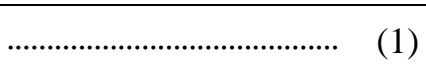 \\
\hline Bak pengumpul : & $=\frac{\mathrm{HRT}}{24 \text { jam } / \text { hari }} \times \mathrm{Q}$ (debit) & 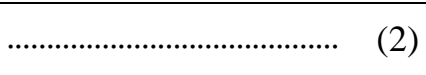 \\
\hline Bak pengendap awal : & $=\frac{\mathrm{HRT}}{24 \mathrm{jam} / \text { hari }} \times \mathrm{Q}$ (debit) & 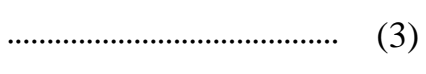 \\
\hline
\end{tabular}

Bak anaerob :

\begin{tabular}{|c|c|}
\hline Beban BOD limbah & $=(\mathrm{Q} \times \mathrm{BOD}$ masuk $)$ \\
\hline Volume media lekat & 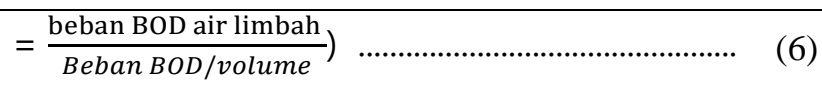 \\
\hline Volume reaktor & 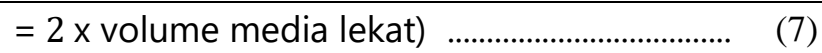 \\
\hline
\end{tabular}

Bak anaerob :

\begin{tabular}{|c|c|c|}
\hline Jumlah BOD dihilangkan & 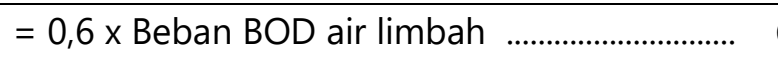 & (9) \\
\hline Volume reaktor/bak & $=\frac{10}{4} \times$ volume media & (10) \\
\hline Total volume media & $=\mathrm{p} \times \mathrm{I} \times \mathrm{v}$ volume media & (11) \\
\hline BOD loading/volume & $=\frac{\text { beban BOD }}{\text { volume Media }}$ & (12) \\
\hline Kebutuhan oksigen & 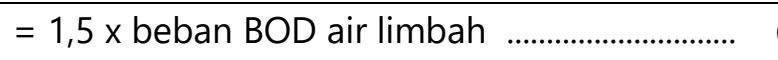 & (13) \\
\hline Kebutuhan udara teoritis & $=\frac{\text { Kebutuhan oksigen }}{\text { berat udara } x \text { oksigen diudara }}$ & (14) \\
\hline Kebutuhan udara aktual & $=\frac{\text { Kebutuhan Udara Teoritis }}{\text { effisiensi difuser }}$ & $(15)$ \\
\hline Jumlah diffuser yang dibutuhkan & $=\frac{\text { total tranfer udara }}{\text { flow rate tipikal }}$ & (16) \\
\hline Bak pengendap akhir : & $=\frac{\mathrm{HRT}}{24 \text { jam } / \text { hari }} \times \mathrm{Q}$ (debit) & $(17)$ \\
\hline Bak biokontrol : & $=\frac{\mathrm{HRT}}{24 \text { jam } / \text { hari }} \times \mathrm{Q}$ (debit) & $(18)$ \\
\hline
\end{tabular}

Keterangan: $\mathrm{Q}=$ debit, $\mathrm{V}=$ volume, $\mathrm{HRT}=$ waktu tinggal bak, $\mathrm{p}=$ panjang, $\mathrm{I}=$ lebar 
Bak pemisah lemak berfungsi untuk untuk memisahkan lemak atau minyak yang masih tersisa. Pada Bak pemisah ditambahkan juga bar screen untuk penyaringan awal terhadap sampah yang mungkin akan masuk ke bak selanjutnya. Bak juga dilengkapi dengan pompa celup untuk mengalirkan air limbah ke bak dengan kapasitas daya hisap 133 liter/menit. Minyak/lemak jika tidak dipisahkan maka akan menyebabkan terhambatnya transfer organik di dalam bak aerasi. Kondisi ini dapat menyebabkan kinerja IPAL kurang maksimal dan mengganggu pengolahan air. Pada bak pemisah lemak ini juga dibutuhkan pengambilan minyak secara manual agar minyak yang sudah terkumpul bisa dihilangkan dari bak tersebut.

\section{Bak Ekualisasi (Pengumpul)}

Dimensi bak ekualisasi (pengumpul) direncanakan berbentuk persegi panjang dengan volume $6,4 \mathrm{~m}^{3}$, dimensi panjang 2,3 $\mathrm{m}$, lebar 2,2 m, tinggi $2 \mathrm{~m}$, tinggi ruang bebas $0,3 \mathrm{~m}$ dan waktu tinggal rata-rata yaitu 6 jam. Air limbah yang berada di bak pemisah lemak kemudian dialirkan ke bak ekualisasi/pengumpul secara gravitasi dengan waktu tinggal 6 jam. Bak ekualisasi berfungsi sebagai bak pengumpul dan menampung keseluruhan air limbah sebelum masuk pada tahap pengolahan air limbah. Bak ini juga berfungsi sebagai tempat untuk menghomogenkan konsentrasi limbah cair serta sebagai pengendap partikel pada air limbah.

\section{Bak Pengendap Awal}

Dimensi bak pengendap awal direncanakan berbentuk persegi panjang dengan volume 4,3 $\mathrm{m}^{3}$, dimensi panjang $1,6 \mathrm{~m}$, lebar $2,2 \mathrm{~m}$, tinggi 2 $\mathrm{m}$, tinggi ruang bebas $0,3 \mathrm{~m}$ dan waktu tinggal rata-rata yaitu 4 jam. Efesiensi pengolahan BOD sebesar $25 \%$ dari BOD awal 124,9 mg/l menjadi 93,7 mg/l. Air limbah dari bak ekualisasi kemudian masuk ke bak pengendap awal dengan waktu tinggal 4 jam.

Bak pengendap berfungsi mengendapkan partikel lumpur, pasir dan kotoran organik tersuspensi. Kotoran padatan tersebut terutama yang berupa lumpur anorganik tidak dapat terurai secara biologis. Jika tidak dihilangkan atau diendapkan akan menempel pada permukaan media biofilter sehingga menghambat transfer oksigen kedalam lapisan biofilm, dan mengakibatkan penurunan efisiensi pengolahan. Selain sebagai bak pengendapan, juga berfungsi sebagai bak pengurai senyawa organik yang berbentuk padatan, sludge digestion (pengurai lumpur) dan penampung lumpur. Lumpur didalam bak pengendap awal harus dikuras secara manual dan berkala.

\section{Bak Anaerob}

Dimensi bak anaerob yang direncanakan berbentuk persegi panjang dengan volume 4,8 $\mathrm{m}^{3}$, dengan dimensi panjang $1,8 \mathrm{~m}$, lebar $2,2 \mathrm{~m}$, tinggi $2 \mathrm{~m}$, tinggi ruang bebas $0,3 \mathrm{~m}$, volume media lekat $2,4 \mathrm{~m}^{3}$, dan waktu tinggal rata-rata yaitu 4 jam serta efesiensi pengolahan BOD sebesar $66,7 \%$ dari BOD awal 93,7 mg/l menjadi $31,2 \mathrm{mg} / \mathrm{l}$.

Air limbah dari bak pengendap awal dialirkan ke bak anaerob (biofilter anaerob) dengan waktu tinggal 4,5 jam. Bak anaerob diisi dengan media khusus dari bahan plastik tipe sarang tawon. Di dalam reaktor biofiter anaerob, penguraian zatzat organik dilakukan oleh bakteri anaerobik, menghasilkan gas methan, amoniak dan gas $\mathrm{H}_{2} \mathrm{~S}$ yang menyebabkan bau tidak sedap. Oleh karena itu untuk pengolahan air limbah pelayanan kesehatan unit reaktor biofilter anaerb dibuat tertutup dan dilengkapi dengan pipa pengeluaran gas.

Setelah beberapa hari pengoperasian, pada permukaan media filter akan tumbuh lapisan film mikroorganisme. Mikroorganisme inilah yang akan menguraikan zat organik yang belum sempat terurai pada bak pengendap awal. Di dalam bak biofilter anaerob juga terdapat media sarang tawon sebagai tempat bakteri tumbuh dan berkembang biak yang berfungsi untuk menguraikan zat-zat yang ada di air limbah.

\section{Bak Aaerob}

Bak aerob direncanakan berbentuk persegi panjang dengan volume $2,9 \mathrm{~m}^{3}$, dimensi panjang 1,2 $\mathrm{m}$, lebar $2,2 \mathrm{~m}$, tinggi $2 \mathrm{~m}$, tinggi ruang bebas $0,3 \mathrm{~m}$, volume media lekat $1,1 \mathrm{~m}^{3}$, dan waktu tinggal rata-rata 2,7 jam. Efesiensi pengolahan BOD sebesar $53,3 \%$ dari BOD awal $31,2 \mathrm{mg} / \mathrm{l}$ menjadi $14,5 \mathrm{mg} / \mathrm{l}$. Kebutuhan oksigen 
sebesar 2,66 $\mathrm{m}^{3} /$ hari, dan kapsitas blower 0,5 $\mathrm{m}^{3} /$ menit yang berjumlah 2 unit.

Fungsi 2 unit blower untuk bekerja secara bergantian. Dilengkapi dengan jumlah 7 buah diffuser yang berjenis fine buble. Dari reaktor biofilter anerob, air limbah dialirkan ke bak aerob dengan waktu tinggal 2,7 jam. Dalam proses pengolahan air limbah dengan sistem biofilter anaerob-aerob reaktor aerobik merupakan unit proses yang dipasang setelah proses biofilter anaerob.

Unit ini berfungsi sebagai tempat terjadinya proses penguraian air limbah secara aerob dengan bantuan injeksi oksigen. Konstruksi reaktor biofilter aerob pada dasarnya sama dengan reaktor biofilter anaerob. Perbedaannya adalah dilengkapi proses aerasi dengan menghembuskan udara melalui diffuser menggunakan blower udara.

Proses aerasi umumnya dilakukan dengan menghembuskan udara melalui diffuser dengan blower udara. Di dalam reaktor biofilter aerob terjadi kondisi aerobik sehingga polutan organik yang belum terurai dalam reaktor biofilter anaerob akan diuraikan menjadi karbon dioksida dan air, sedangkan amoniak atau amonium yang terjadi pada proses biofilter anaerob akan dioksidasi (proses nitrifikasi) diubah menjadi nitrat (NH4+NO3). Di dalam reaktor aerob dapat di tambahkan bakteri E4 untuk mempercepat penguraian secara biologi. Di dalam bak biofilter anaerob ini juga terdapat media sarang tawon sebagai tempat bakteri tumbuh dan berkembang biak yang berfungsi untuk menguraikan zat-zat yang ada di air limbah.

\section{Bak Pengendap Akhir}

Bak pengendap akhir yang direncanakan berbentuk persegi panjang dengan volume 4,3 $\mathrm{m}^{3}$, dimensi panjang $1,6 \mathrm{~m}$, lebar $2,2 \mathrm{~m}$, tinggi 2 $\mathrm{m}$, tinggi ruang bebas $0,3 \mathrm{~m}$ dan waktu tinggal rata-rata yaitu 4 jam. Efesiensi pengolahan BOD sebesar $25 \%$ dari BOD awal $14,5 \mathrm{mg} / \mathrm{l}$ menjadi 10,8 mg/l. Air limbah dialirkan ke bak pengendap akhir dengan waktu tinggal 4 jam. Bak pengendap akhir berfungsi mengendapkan kembali padatan tersuspensi yang masih tersisa di pengolahan akhir seperti pasir, lumpur dan padatan dalam air limbah. Lumpur didalam bak pengendap akhir harus dikuras secara manual dan berkala.

\section{Bak Biokontrol}

Dimensi bak pengendap akhir irencanakan berbentuk persegi panjang dengan volume 4,3 $\mathrm{m}^{3}$, dimensi panjang $1,6 \mathrm{~m}$, lebar $2,2 \mathrm{~m}$, tinggi 2 $m$, tinggi ruang bebas 0,3 . Air Limbah kemudian mengalir ke bak biokontrol, yang berfungsi untuk melihat apakah kandungan dalam air limbah masih berbahaya untuk kehidupan biota air seperti ikan. Secara singkat dapat disimpulkan jika ikan dapat hidup dengan baik maka parameter yang terkandung dalam air limbah dapat dibuang ke badan air.

\section{Bak Klorinasi}

Dimensi bak pengendap akhir direncanakan berbentuk persegi panjang dengan volume $2 \mathrm{~m}^{3}$, dimensi panjang 2,2 $\mathrm{m}$, lebar 1,2 $\mathrm{m}$, tinggi (1) 2 $\mathrm{m}$, tinggi (2) $1,5 \mathrm{~m}$. Air Limbah kemudian dialirkan dari bak biokontrol masuk ke bak klorinasi dengan waktu tinggal selama 30 menit (Said, 2018), bak klorinasi sebagai proses terakhir yang bertujuan untuk membunuh kuman dan mengoksidasi bahan-bahan kimia dengan penambahan cairan klor dalam air limbah, yang mungkin masih tersisa. Kemudian air dari bak klorinasi dialirkan kesaluran drainase.

Tabel 1. Hasil Perhitungan Dimensi IPAL dengan debit 25,7 m³/hr

\begin{tabular}{|c|c|c|c|c|c|c|}
\hline No & Unit Bak & $V\left(m^{3}\right)$ & $P(m)$ & $L(m)$ & $\mathrm{T}(\mathrm{m})$ & DT (jam) \\
\hline 1. & Bak Pemecah Lemak & 2,1 & 0,9 & 2,2 & 2 & 1 \\
\hline 2. & Bak Ekualisasi & 6,4 & 2,3 & 2,2 & 2 & 6 \\
\hline 3. & Bak Pengendap Awal & 4,3 & 1,6 & 2,2 & 2 & 4 \\
\hline 4. & Bak Biofilter Anerob & 4,8 & 1,8 & 2,2 & 2 & 4,5 \\
\hline 5. & Bak Biofilter Aerob & 2,9 & 1,2 & 2,2 & 2 & 2,7 \\
\hline 6. & Bak Pengendap Akhir & 4,3 & 1,6 & 2,2 & 2 & 4 \\
\hline 7. & Bak Biokontrol & 4,3 & 1,6 & 2,2 & 2 & - \\
\hline
\end{tabular}

Keterangan $: \mathrm{V}=$ volume, $\mathrm{P}=$ panjang, $\mathrm{L}=$ Lebar, $\mathrm{T}=$ kedalaman efektif dan $\mathrm{DT}=$ Waktu Tinggal (detention Time) 


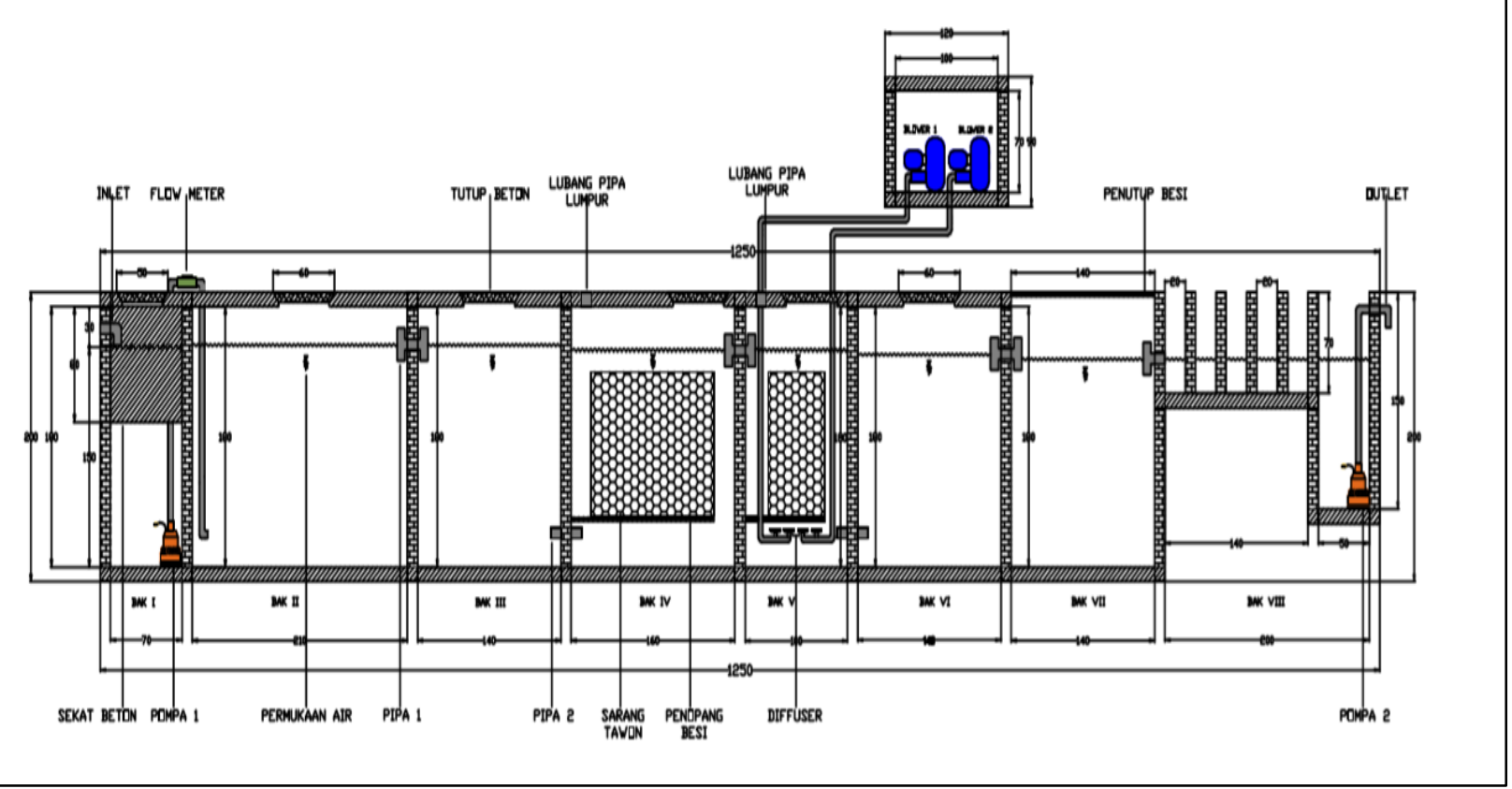

Gambar 1. Desain IPAL Puskesmas Rawat Inap Way Halim Kota Bandar Lampung

Gambar 1 merupakan hasil perencanaan IPAL dengan sistem Biofilter anaerob-aerob secara keseluruhan. Berdasarkan hasil perhitungan biaya konstruksi, maka perkiraan biaya yang dibutuhkan untuk pembangunan IPAL sebesar Rp.156.000.000 (Tabel 2). RAB disusun berdasarkan harga satuan upah, bahan dan peralatan Kota Bandar Lampung tahun 2020 dan analisis harga satuan pekerja tahun 2020 yang telah sesuai dengan SNI yang berlaku.

Tabel 2. Perkiraan biaya pembangunana IPAL

\begin{tabular}{lll}
\hline No & Jenis Pekerjaan & Jumlah \\
\hline 1 & Pekerjaan persiapan & Rp 249.180, \\
2 & Pekerjaan tanah & Rp 6.717.775,- \\
3 & Pekerjaan dinding & Rp 7.716.070,- \\
4 & Pekerjaan plesteran & Rp 8.699.280,- \\
5 & Pekerjaan beton & Rp 56.205.152,- \\
6 & Pekerjaan lain-lain & Rp 61.811.837,- \\
7 & Pajak (10\%) & Rp 14.139.929,- \\
\hline & Jumlah & Rp.156.000.000,- \\
\hline
\end{tabular}

\section{SIMPULAN}

Perencanaan disusun berdasarkan debit air limbah yang dihasilkan $\left(25,7 \mathrm{~m}^{3}\right)$, dan mengikuti ketetapan yang berlaku. Jenis dan volume masing-masing bak pengolahan berdasarkan hasil perhitungan adalah: bak pemisah lemak $\left(2,1 \mathrm{~m}^{3}\right)$, bak ekualisasi $\left(6,4 \mathrm{~m}^{3}\right)$, bak pengendap awal $\left(4,3 \mathrm{~m}^{3}\right)$, bak anaerob $\left(4,8 \mathrm{~m}^{3}\right)$, bak aerob $\left(2,9 \mathrm{~m}^{3}\right)$, bak pengendap akhir $\left(4,3 \mathrm{~m}^{3}\right)$, bak biokontrol $\left(4,3 \mathrm{~m}^{3}\right)$, dan bak klorinasi $\left(1 \mathrm{~m}^{3}\right)$.
Sedangkan kebutuhan biaya pembangunan IPAL sebanyak Rp 156.000.000,-. IPAL diyakini mampu menurunkan kadar BOD sebesar 94\% (efisiensi) dari BOD awal adalah 124,9 mg/l menjadi 10,8 $\mathrm{mg} / \mathrm{l}$.

\section{DAFTAR PUSTAKA}

Asmadi dan Suharno. (2012). Dasar Dasar Teknologi Pengolahan Air Limbah (Tim Gosyen, ed.). pontianak: Gosyen Publishing.

Hariyani, N., \& Sarto, S. (2018). Evaluasi 
penggunaan biofilter anaerob-aerob untuk meningkatkan kualitas air limbah rumah sakit. Berita Kedokteran Masyarakat, 34(5), 199-204. https://doi.org/https://doi.org/10.22146/bkm.3 5092

Kementerian Kesehatan RI. (2011). Pedoman Teknis Dengan Sistem Biofilter anaerob-aerob Pengolahan Air Limbah Instalasi Pada Fasilitas Pelayanan Kesehatan. In DIREKTORAT BINA PELAYANAN PENUNJANG MEDIK DAN SARANA KESEHATAN.

Kementerian Kesehatan RI. (2019a). Data puskesmas dilndonesia. Jakarta: Kementerian Kesehatan RI.

Kementerian Kesehatan RI. Peraturan Menteri Kesehatan. No 43 Tentang Puskesmas. , (2019). Kementerian Kesehatan RI. Peraturan Menteri Kesehatan. No 7 Tahun 2019 Tentang
Persyaratan Kesehatan Lingkungan Rumah Sakit. , (2019).

Said, N. I. (2018). Paket Teknologi Pengolahan Air Limbah Rumah Sakit Yang Murah Dan Efisien. Jurnal Air Indonesia, 2(1), 52-65. https://doi.org/10.29122/jai.v2i1.2289

Timpua, T. K., \& Pianaung, R. (2019). Uji Coba Desain Media Biofilter anaerob-aerob Dalam Menurunkan Kadar BOD, COD, TSS dan Coliform Limbah Cair Rumah Sakit. Jurnal Kesehatan Lingkungan, 9(1), 75-80. https://doi.org/10.47718/jkl.v9i1.646

Widayat, W., \& Said, N. I. (2017). Rancang Bangun Paket IPAL Rumah Sakit Dengan Proses Biofilter Anaerob-Aerob, Kapasitas 20-30 M3 Per Hari. Jurnal Air Indonesia, 1(1). https://doi.org/10.29122/jai.v1i1.2283 